Anat. Labor. of Prof. H. SETO, Tohoku University, Sendai.

\title{
Histological Study on the Sensory Innervation of the Perivulval Skin of Female Formosan Macaque.
}

雌台湾猿の外陰部周囲皮膚の知覚神経分布に関する組織学的研究.

\section{Toshiyuki YAMAMOTO, Ryuji NAKAI, Mitsuo NISHIO, Susumu KAWAZU and Nobuko HIRAISHI.}

\author{
山本敏行, 中拈隆治, 西尾光男, 川津進と平石宣子.
}

(Received Delember 14, 1959.)

Recently, the present autors have conducted a histological study on the sensory nerve supply of the labium minus pudendi and the vestibulum vaginae of the Formosan macaque and arrived at some interesting findings. Next to it, asimilar study has been undertaken on the perivulvar skin of the same macaque, and found that its fine structure and sensory innervation are markedly dissimilar to these of the common haired skin, as reported hereunder.

The materials for our study sampled from some mature female Formosan macaques were fixed for a long time in $10 \%$ neutral formol solution, cut into $40 \mu$ frozen sections and stained by SETO's silver impregnation method.

\section{Individual Findings.}

Our so called perivulva of the Formosan macaque is a special skin part located between the labium minus pudendi and the ischial callosity and very poor in folds and hairs. A shallow depression partitions it off from the labium minus, but between it and the hairless ischial callosity there is no notable furrow. No such a labium majus pudendi as seen in the human vulva is present in the female Formosan macaque as in many other catarrhine monkeys (WISLOCKI 1936, ASHLEY-MONTAGU 1937).

The fine structure of the perivulvar skin, as shown in Fig. 1, is markedly different from that of the common haired skin. The epidermis here is considerably thick and has a thick undesquamating cornified layer or plate and no folds on its surface. The corium of rather dense fibrous connective tissue sends regularly arranged long papillae into the epidermis. A small quantity of smooth muscle fibres are contained in the corium, giving the skin of this part the usual characteristic of a sexual skin, but as no sweat glands or sebaceous glands are found and hair follicles are absent here, this part is not to be looked upon as corresponding to the labium majus pudendi of the human or some simian vulvae. The well-developed epidermis and papillae here are similar to those in the hairless skin of the hand palm and the foot sole.

According to many an observation at this laboratory, the sensory nerve supply of an area covered by a stratified flat epithelium or epidermis shows parallelism with the development of the papillae growing out of the underlying connective tissue into the epithelium or epidermis, that is to say, the nerve supply is the more powerful, 


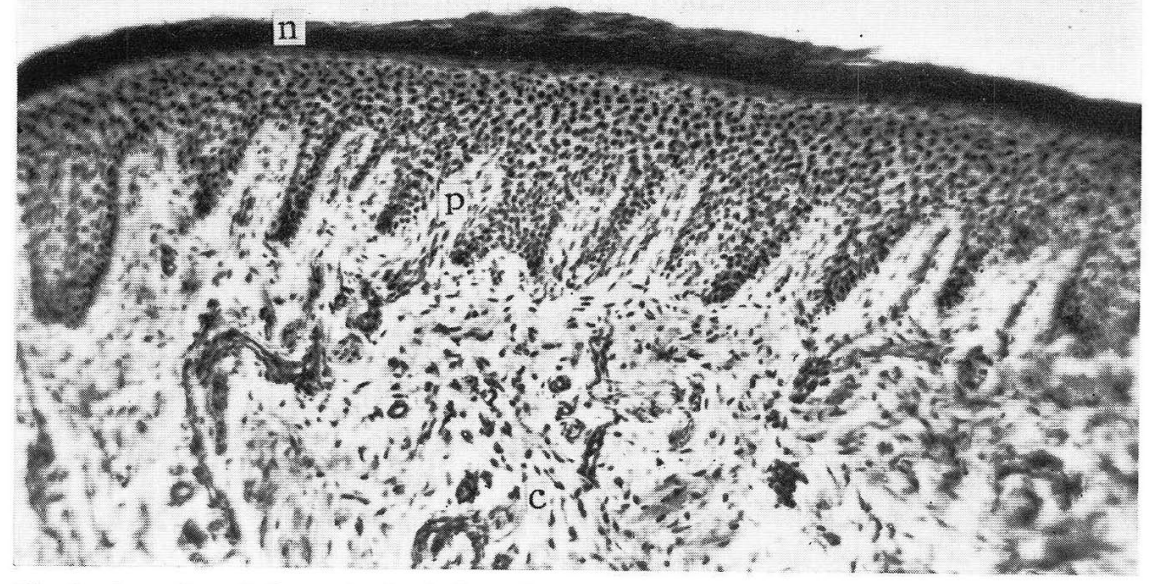

Fig. 1. A section of the perivulval skin of a female Formosan macaque. $n$ non-desquamating cornified layer, $p$ well-developed long papilla from the corium $(c)$. SETO's impregnation. Photo $\times 100$.

the better the papillary formation. The perivulvar part of the Formosan macaque having considerably stout papillae growing out of the well-developed corium into the epidermis, we could easily anticipate to find the part rich in sensory terminations

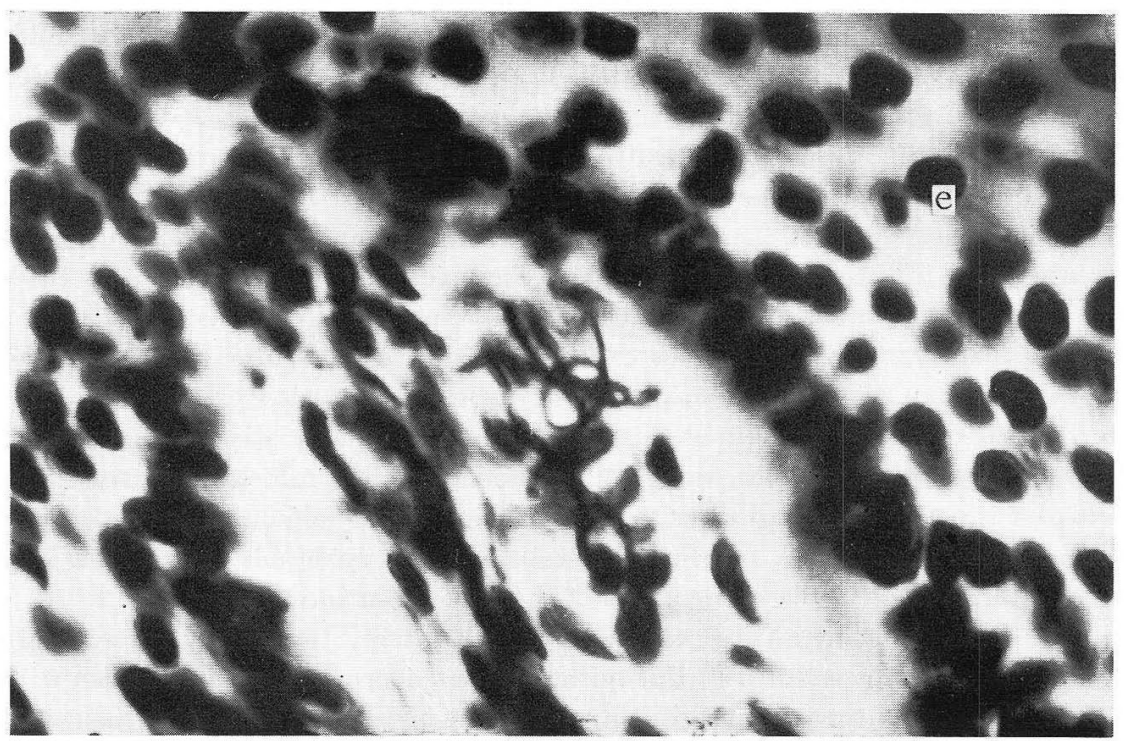

Fig. 2. A corpuscular sensory termination Type I (glomerular arrangement of the branch fibres) found in a papilla in the perivulval skin of a Formosan macaque. $e$ epidermis. Details in the text. Same staining. Photo $\times 800$. 
and in fact, we were not betrayed in our anticipation.

Usually, the majority of the sensory nerve fibres coming into a haired skin end as hair-nerve fibres in the hair-follicle necks, and only a very few of them run to the underside of the epidermis to end in unbranched or very simple branched terminations there. In the hairless skin of the perivulvar part of our Formosan macaque, however, the sensory fibres running toward the epidermis were very numerous and these formed not only unbranched and simple branched terminations but frequently also more refined corpuscular or complex branched terminations. It is of interest that intraepidermal terminations were not rare here either.

Previously, we have classified the corpuscular terminations we found in the histological study on the labium minus pudendi and the vestibulum vaginae of Formosan macaque into 4 types. The labium minus was found to contain corpuscles of Types I, II and III, the vaginal vestibule those of Type II in the main and the existence of 'Type IV bodies or PACINIan bodies was demonstrated in the depth of the shallow depression just outside the labium minus. Now, the corpuscular terminations found in the perivulvar skin belong to the Type I above.

Two of such end-bodies are exemplified in Figs. 2 and 3. A thick myelinated

Fig. 3. Ditto. $n$ neurofibrillar expansion, e epidermis. Same staining. Photo $\times 1800$.

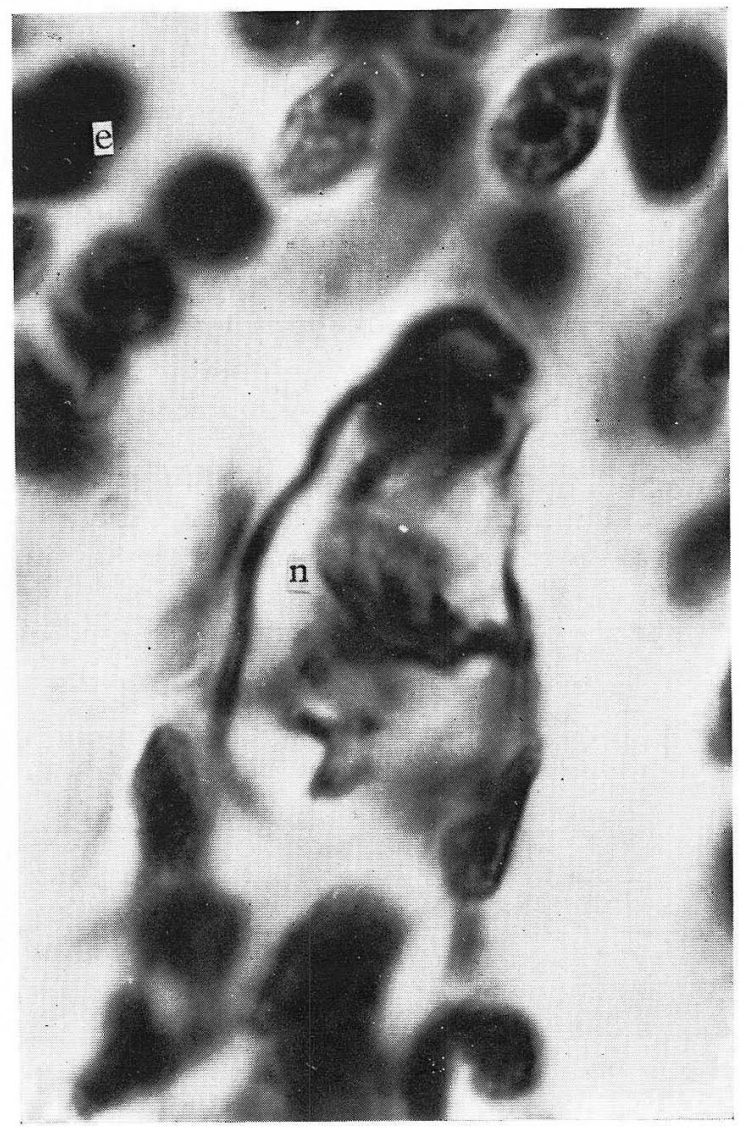


fibre, upon reaching a papilla, loses its myel'n sheath and enters the inner bulb containing a few cell nuclei and branches out herein into several branch fibres showing conspicuous change in size while running peculiar winding courses and undergoing

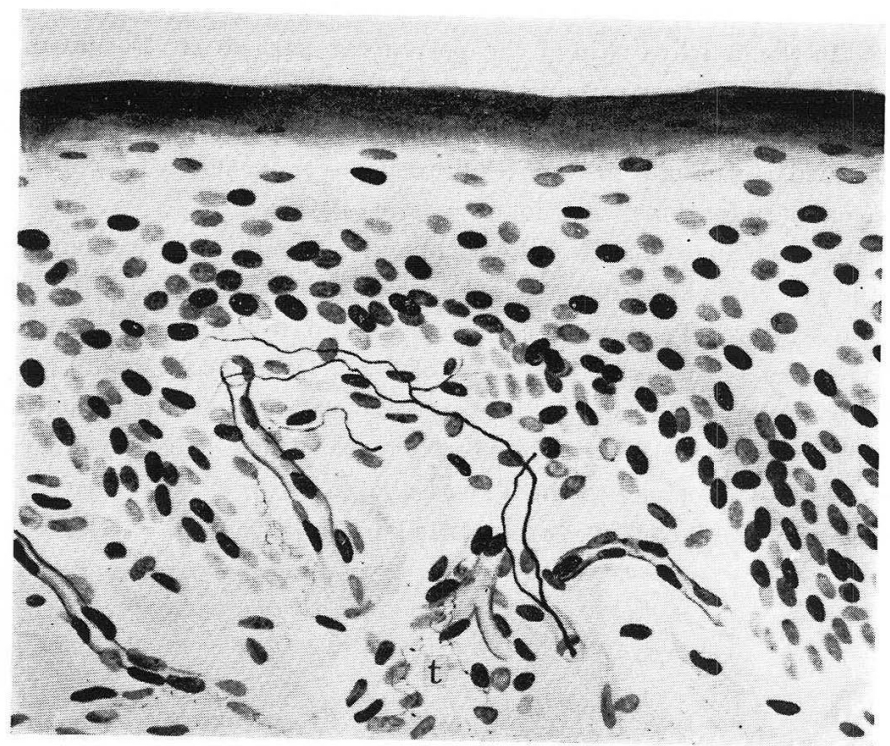

Fig. 4. A complex branched sensory termination found in a papilla in the perivulval skin of a Formosan macaque. $t$ terminal reticulum. Same staining. $\times 400$.

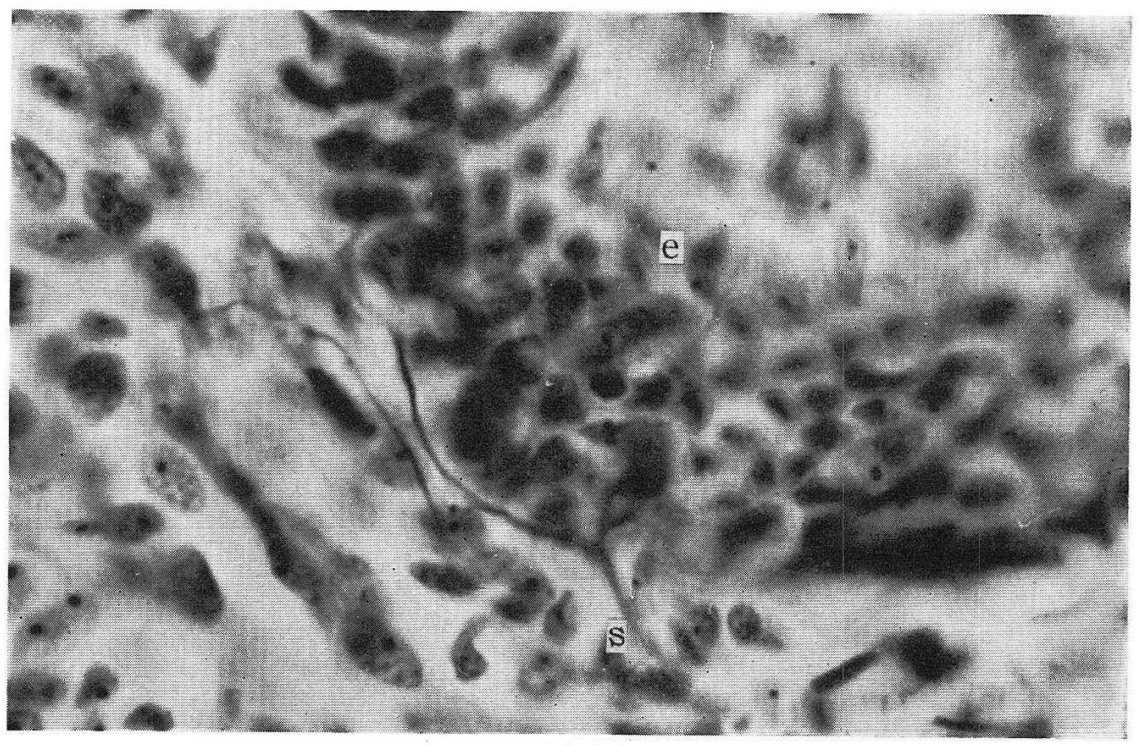

Fig. 5. Ditto. $e$ epidermal crista, s stem nerve fibre. Details in the text. Same staining. Photo $\times 800$. 
frequent mutual anstomosis, thus ending in a general arrangement of a glomerulus. The branch fibres often end in sharp points, but more often in expansions of extremely fine neurofibrils, rarely showing distinct free ends. Such corpuscular terminations are found also in the lip (YAMAMOTO et al. 1958) and the anus (Ditto 1959) and are undoubtedly of a high-class type among the sensory terminations.

Examples of complex branched terminations are shown in Figs. 4, 5 and 6. The unbranched and the simple branched terminations usually originate in comparatively thin stem fibres, but these complex branched terminations always originate in myelinated fibres of more than medium size, not rarely in exceptionally thick fibres (Fig. 6).

In the branched termination illustrated in Fig. 4, the stem fibre, after losing its myelin sheath in the middle of the papilla, by repeated bifurcation gives out finer branches, which run surfacewards and end sharply just deneath the epidermis. In Fig. 5 we see a sensory stem fibre running into the vicinity of basis of an epidermal crista between two papillae and then branching out into a few branches showing slight change in size; these branch fibres run up along the sides of the epidermal crista, then branch out again, the terminal fibres finally tapering off into sharp points subepidermally.

In the rather complex branched termination illustrated in Fig. 6, the very thick stem fibre loses its myelin sheath in the middle of the papilla and branches out into many branch fibres showing somewhat conspicuous change in size; the terminal branches mostly run close up to the epidermis and end then in sharp or blunt points, but a single one of them runs further into the epidermis and ends sharply near the cornified layer. Such intraepidermal fibres are interesting entities, since they are

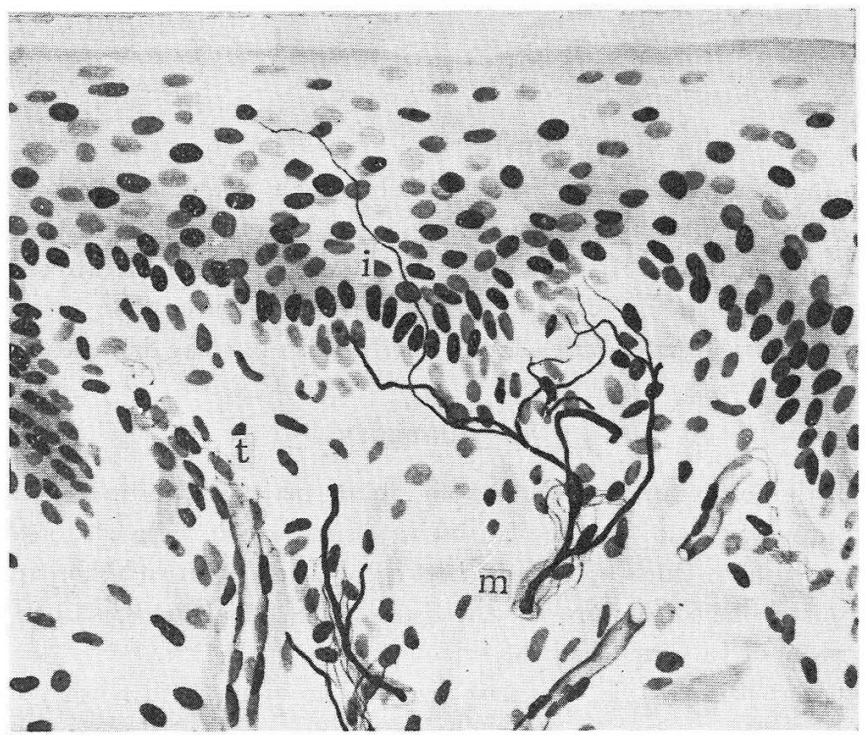

Fig. 6. Ditto. The cornified layer of the epidermis has been artificially shed during preparation. $m$ myelinated very thick stem fibre, $i$ intraepidermal fibre, $t$ vegetative terminal reticulum. Sa me staiuing. $\times 400$. 


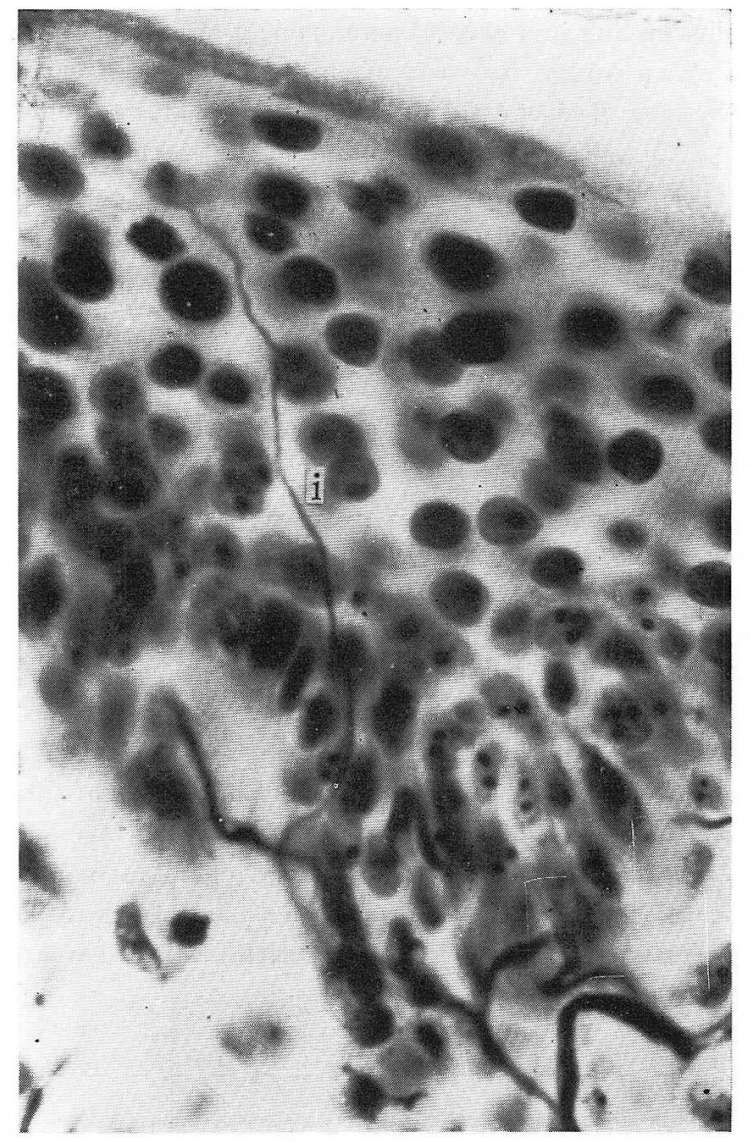

Fig. 7.

Higher magnification of part of Fig. 6.

$i$ intraepidermal fibre.

never to be found in the common haired skin having a desquamating cornified layer. In Fig. 7 is shown the termination seen in Fig. 6 in microphotographic representation of higher magnification. Here the change in size and the intricate courses of the branch fibres are clearly illustrated as they are in nature. The inter- and intracellular courses of the intraepidermal fibre (i) is also in clear delineation here.

\section{Summary.}

The female Formosan macaque has no labium majus pudendi. The part between the labium minus pudendi and the ischial callosity which we wish to call the perivulva is covered by a thick epidermis with a cornified plate and the papillae growing into it out of the corium are very well developed, recalling what has been observed in the palm of the hand and the sole of the foot.

This special skin part is considerably well provided with sensory nerve fibres to match such a histological feature. The numerous sensory fibres coming into this part end not only in unbranched and simple branched terminations but also in corpus. cular terminations or complex branched terminations never found in the common 
haired skin. Intraepidermal branched terminations are not rare either. The corpuscular terminations here are of the Type I of end-bodies (YAMAMOTO) and show glomerular arrangement. The complex branched terminations originate in stem fibres thicker than those of the unbranched and the simple branched terminations; their numerous branch fibres often show change in size and end either sharply or bluntly just beneath the epidermis, but in some cases in the epidermis, and even far up near its cornified surface layer.

\section{内 容 自 抄}

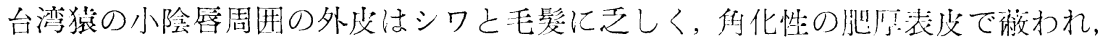

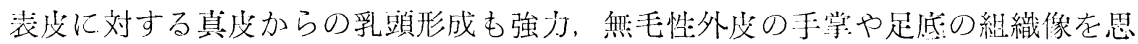
わせる。徒ってての部は甚だ知覚線維に富み，表攴下には非分岐性及び単純性分 岐性終末は勿諭，太さの変化に富んだ太い終末枝から成る複雑性分岐性紷末湴び

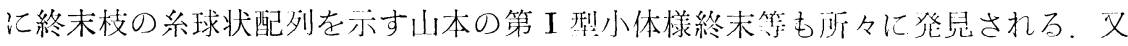
表支内に進んで終る表攴内線維も稀ならず詐明される。

\section{References.}

Ashley-Montagu, M. F.: Note on the external genitalia in three female old world primates. Anat. Rec. 69 (1937). - Wislocki,G. B.: The external genitalia of the the simian primates. Human Biol. 8 (1936). - Yamamoto, T., I. Ito, T. Ohno, H. Ohyama a. Sh. Seino: Histology and sensory innervation of transitional and mucosal parts of the lip of monkey. Arch. hist. jap. 14 (1958). - Yamamoto, T., T. Ashino, K. Fukase, T. Suenaga a. S. Sekiguchi: Histological study on the innervation, especially, sensory innervation of the anus of Formosan macaque. Ibid. 19 (1960). - Yamamoto, T., Sh. Hatakeyama, M. Kikuchi a. T. Yamaguchi : On the sensory innervation of the labium minus pudendi and the vestibulum vaginae in Formosan macaque. Ibid. 19 (1960). 